\title{
Induced hydrophobicity in micro-and nanostructured nickel thin films obtained by ultraviolet pulsed laser treatment
}

DOI:

10.1002/pssa.201600101

\section{Document Version}

Accepted author manuscript

Link to publication record in Manchester Research Explorer

Citation for published version (APA):

Framil Carpeño, D., Dickinson, M., Seal, C., \& Hyland, M. (2016). Induced hydrophobicity in micro-and nanostructured nickel thin films obtained by ultraviolet pulsed laser treatment. Physica Status Solidi $(A)$ Applications and Materials Science. https://doi.org/10.1002/pssa.201600101

Published in:

Physica Status Solidi (A) Applications and Materials Science

\section{Citing this paper}

Please note that where the full-text provided on Manchester Research Explorer is the Author Accepted Manuscript or Proof version this may differ from the final Published version. If citing, it is advised that you check and use the publisher's definitive version.

\section{General rights}

Copyright and moral rights for the publications made accessible in the Research Explorer are retained by the authors and/or other copyright owners and it is a condition of accessing publications that users recognise and abide by the legal requirements associated with these rights.

\section{Takedown policy}

If you believe that this document breaches copyright please refer to the University of Manchester's Takedown Procedures [http://man.ac.uk/04Y6Bo] or contact uml.scholarlycommunications@manchester.ac.uk providing relevant details, so we can investigate your claim.

\section{OPEN ACCESS}




\section{Physica Status Solidi A: Applications and Materials Science Induced hydrophobicity in micro- and nanostructured nickel thin films obtained by ultraviolet pulsed laser treatment \\ --Manuscript Draft--}

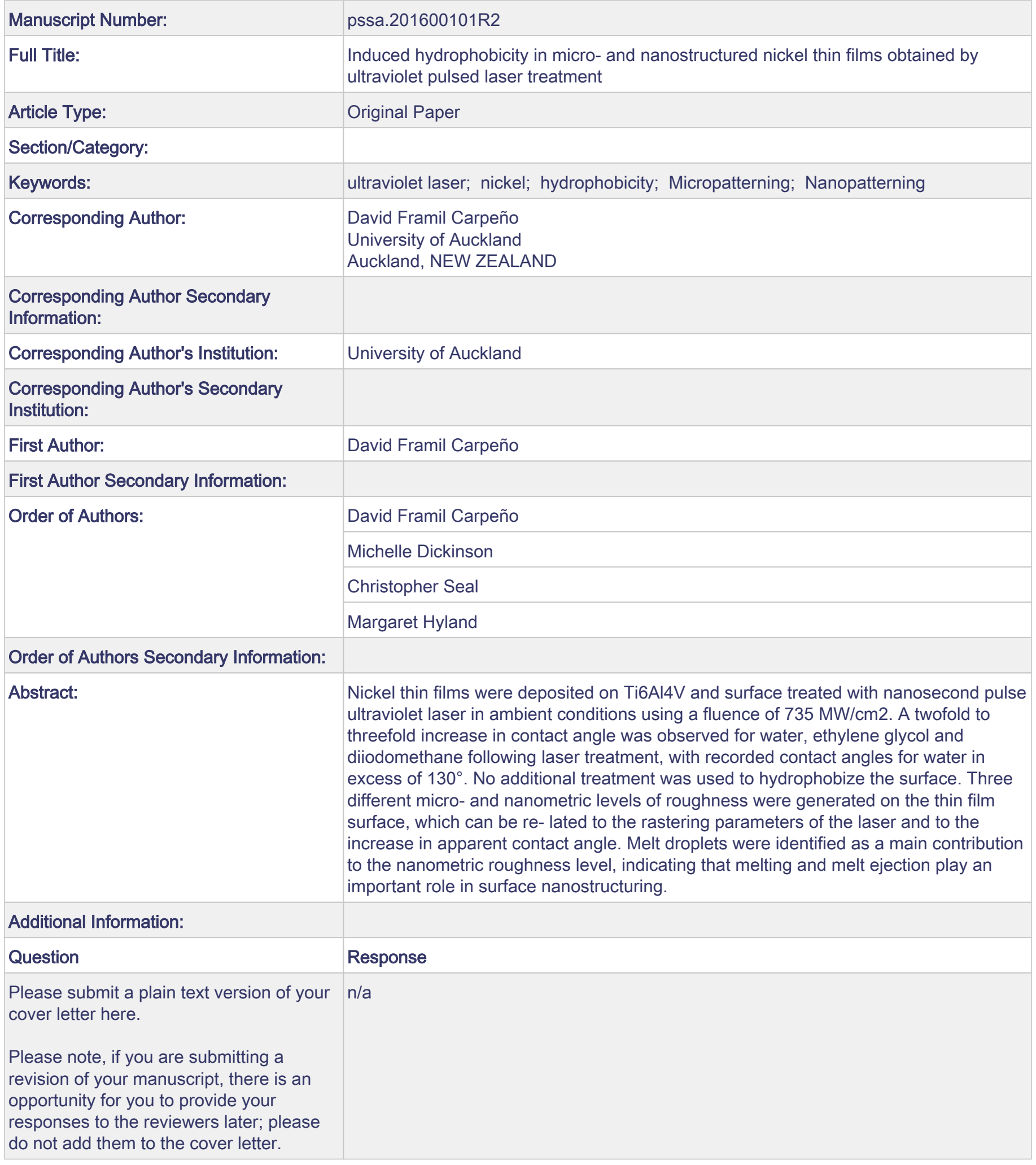




\begin{abstract}
Nickel thin films were deposited on Ti6Al4V and surface treated with nanosecond pulse ultraviolet laser in ambient conditions using a fluence of $3.68 \mathrm{~J} / \mathrm{cm}^{2}$. A twofold to threefold increase in contact angle was observed for water, ethylene glycol and diiodomethane following laser treatment, with recorded contact angles for water in excess of $130^{\circ}$. No additional treatment was used to hydrophobize the surface. Three different micro- and nanometric levels of roughness were generated on the thin film surface, which can be related to the rastering parameters of the laser and to the increase in apparent contact angle. Melt droplets were identified as a main contribution to the nanometric roughness level, indicating that melting and melt ejection play an important role in surface nanostructuring.
\end{abstract}

Keywords:

ultraviolet laser, nickel, hydrophobicity, micropatterning, nanopatterning

\title{
1. Introduction
}

Hydrophobic surfaces, especially superhydrophobic ones, are of interest because of their excellent repelling, anti-sticking and self-cleaning characteristics [1-6]. Surface micro- and nanopatterning is widely used to create

\footnotetext{
*Email, david.framil-carpeno@auckland.ac.nz; Phone, +64 211911246 
hierarchical structures needed to induce surface hydrophobicity and superhydrophobicity. Traditional approaches generally rely on structuring an already hydrophobic surface or on hydrophobizing a rough hierarchically-structured surface, employing a broad range of techniques and materials [1, 7-16]. Micro- and nanopatterning can also be achieved with lasers, however their use as a procedure to induce direct hydrophobicity and superhydrophobicity in metallic surfaces is only emerging. Recent studies have used picosecond to nanosecond pulsed lasers with infrarred to ultraviolet wavelengths to successfully induce superhydrophobicity in platinum [17], brass [17-19], iron and stainless steels [20-25], titanium and Ti6Al4V [17, 20-22], silicon [26], copper $[18,22]$, cobalt [22], aluminium [22, 27] or carbon nanotubes [28]. No such surface patterning has been reported on nickel to date.

\section{Experimental section}

Annealed Ti6Al4V samples (15 x $15 \times 2 \mathrm{~mm})$ were ground using silicon carbide paper, and further wet-polished using a suspension of $3 \mu \mathrm{m}$ size diamond particle. A final polishing step using a solution containing $0.04 \mu \mathrm{m}$ size alkaline silica particle dispersed in hydrogen peroxide was employed.

Nickel thin films were deposited from pure nickel targets by means of glow discharge $\mathrm{Ar}^{+}$plasma-sputtering at GNS Science in Lower Hutt, Wellington. Three different Ti6Al4V substrates were nickel-coated simultaneously in the sputtering chamber, obtaining an average thin film thickness of approximately $900 \mathrm{~nm}$.

Thin films were further laser-treated in standard room conditions at the Photon Factory in the University of Auckland with a KrF excimer UV laser (Xantos XS, Coherent) of $248 \mathrm{~nm}$ emission wavelength and a pulse duration of $5 \mathrm{~ns}$. The experimental assembly provides a beam with spatial profile of $6 \times 3 \mathrm{~mm}$ and beam divergence of $2 \times 1 \mathrm{mrad}$. The four parameters that could be varied included input power, mask size, repetition rate, and number of pulses. To ensure full treatment of the surface a rastering configuration was adopted, whereby the laser spot was scanned over the surface line by line ensuring that a fixed number of pulses per region was delivered following each laser pass. To compensate for any slight misalignment of the laser system and the material response, the distance between consecutive rastered lines was set to be $2 \mu \mathrm{m}$ less than the size of the square mask, thus potentially giving rise to an overlapping of $1 \mu \mathrm{m}$ on each side of the line. The complete laser parameters of the experiment are provided in table 1. 
Table 1: Experimental laser parameters.

\begin{tabular}{|c|c|}
\hline Base substrate & Ti6Al4V \\
\hline Sputtered coating, thickness $(\mathrm{nm})$ & $\mathrm{Ni}, 900$ \\
\hline Mask size $(\mu \mathrm{m})$ & $50 \times 50$ \\
\hline Number of pulses per area $\left(\mu \mathrm{m}^{-2}\right)$ & $4 \times 10^{-3}$ \\
\hline Repetition rate $(\mathrm{Hz})$ & 500 \\
\hline Input power $(\mathrm{mW})$ & 46 \\
\hline Fluence per pulse $\left(\mathrm{J} / \mathrm{cm}^{2}\right)$ & 3.68 \\
\hline Rastering step $(\mu \mathrm{m})$ & 5 \\
\hline Vertical line separation $(\mu \mathrm{m})$ & 48 \\
\hline
\end{tabular}

Surface treated samples were cleaned in water with detergent and blowndried with ethanol, and subsequently contact angle measurements were performed with a KSV CAM 200 goniometer using a sessile drop technique assembly equipped with a CCD camera. Drops of water, ethylene glycol or diiodomethane were poured with a syringe onto the laser treated surfaces and the contact angle was measured using the CAM 200 software to fit the shape of the drop to a curve and calculate the angle via the intersection with a baseline that matches with the substrate. Due to sensitivity in the substrate recognition by the software, baselines had to be fit manually in some cases. Thirty values of contact angle were taken within the minute after the droplet was deposited and the average was calculated.

A FEI (Philips) XL30 S-FEG scanning electron microscope (SEM) was used to obtain surface images using secondary electrons. Scanning Probe Microscopy (SPM) images were taken with a cube corner nanoindentation tip (Hysitron TI950 TriboIndenter) by rastering the tip over the surface while exerting a very low force of $2 \mu \mathrm{N}$. In this way, topographical information about the surface can be extracted.

\section{Results}

The effect of UV-laser treatment on surface morphology of nickel thin films can be observed in figures 1 and 2. Freshly sputtered nickel thin films show grainy cauliflower-like features homogeneously distributed throughout the surface, while laser-treated films display three distinct roughness levels. 
The first one consists of periodic and relatively dense lines of approximately 3 $\mu \mathrm{m}$ thickness separated by a period of $50 \mu \mathrm{m}$. The vertical dimensions could not be unmistakably estimated by SPM due to a combination of the height of the features, the intricate topography, and the piezo vertical limit, however recorded values suggest heights in excess of $2 \mu \mathrm{m}$. The second roughness level is located between the dense lines and consists of periodic thin lines of $50 \mu \mathrm{m}$ length separated by a period of approximately $5 \mu \mathrm{m}$, and formed by the alignment of large melted and solidified droplets of roughly $500-700$ $\mathrm{nm}$ size and $300-600 \mathrm{~nm}$ height. Crater/donut morphologies and dragging of the droplets can also be identified. The third roughness level corresponds to the region between the thin lines, which is mainly formed by melted and solidified droplets of $200400 \mathrm{~nm}$ size and less than $300 \mathrm{~nm}$ height, either solid or crater-shaped.

Average contact angles measured during the first minute are plotted in figure 3 before and after laser treatment. On freshly sputtered nickel, measured contact angles are $41.5 \pm 4.2^{\circ}$ for water, $33.3 \pm 0.9^{\circ}$ for ethylene glycol, and $27.0 \pm 0.4^{\circ}$ for diiodomethane. The values following laser treatment are $128.2 \pm 6.2^{\circ}$ for water, $95.7 \pm 5.9^{\circ}$ for ethylene glycol, and $56.2 \pm 6.0^{\circ}$ for diiodomethane, which correspond to a twofold to threefold increase in contact angle. The effect of laser treatment can be observed in figure 4 for water, where angles in excess of $130^{\circ}$ were measured.

\section{Discussion}

The roughness levels observed can be understood in terms of the laser interaction with the material surface. Under conditions of low energy deposition rates such as the ones found in nanosecond laser pulses, melting initiates heterogeneously from surfaces and crystal defects [29], and the extent of the heat affected zone can be estimated by the heat diffusion length into the material [30-32], which depends on its thermal diffusivity and the laser pulse duration. This would yield a heat-affected region of approximately 510 nm per pulse for nickel $[33,34]$, however the total extent of the heat affected region varies because it also depends on the number of pulses and the type of heat conduction [35].

Numerical models have predicted an increased mass flow rate at the edges of the irradiated zone as a consequence of a spatial plasma pressure variation [36], although other mechanisms such as explosive ablation can also generate crater morphologies with grooves of different depths depending on the laser 
Figure 1: SEM micrographs of sputter-coated nickel thin film: a), b) before and c), d) after laser treatment.

machining parameters and ablation efficiencies [37-42]. Surface features such as droplets and the use of a moderate fluence $<7 \mathrm{~J} / \mathrm{cm} 2[37]$ point towards pressure-induced melt displacement being the main mechanism behind the generation of the surface morphology, with some melt instability that results in droplet ejection and recondensation on the surface [43]. In this context, 
Figure 2: SPM image of laser-treated nickel thin film, clearly displaying the two roughness levels shown in figure 1d).

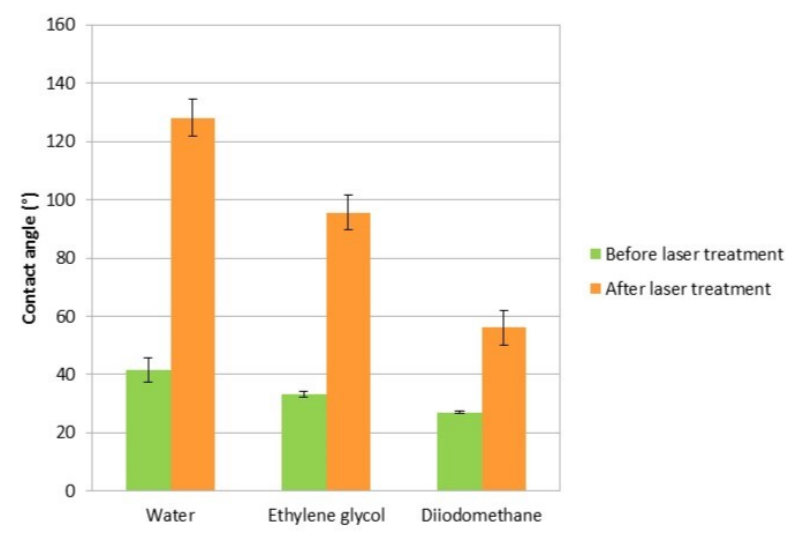

Figure 3: Average contact angle before and after laser treatment for water, ethylene glycol and diiodomethane on nickel thin film.

the observed craters could be the consequence of bubble entrapment during melt pool solidification [44-46], or bubble formation at the interface between redeposited ejected droplets and the solid substrate [47]. The use of a 50 $\mu \mathrm{m}$ mask would therefore create the features observed experimentally, with $50 \mu \mathrm{m}$-period higher walls in parallel to the scanning direction and smaller periodic lines in perpendicular. These latter features arise as a consequence of 


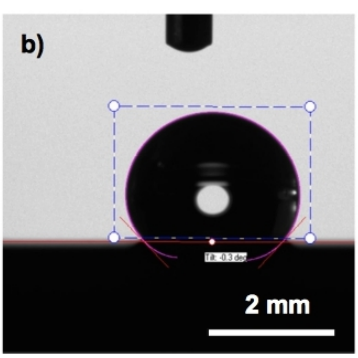

Figure 4: CCD camera image of sessile drop experiment for water on sputter-coated nickel thin film a) before and b) after laser treatment. The apparent contact angle measured after laser treatment is in excess of $130^{\circ}$.

the $5 \mu \mathrm{m}$ rastering laser step and are not to be confused with laser induced ripples, which are sub-wavelength structures that form as a result of laser interference [48-51].

Laser-induced micro- and nanostructuration induces an increase in the apparent contact angle which is independent on the polarity of probing liquid employed, and the ratio between the contact angles before and after laser treatment would rule out the existence a roughness-induced Wenzel state in favour of a Cassie-Baxter state [7, 52]. Even if a Wenzel state was generated due to the cauliflower-like morphology of freshly sputtered nickel thin films, values reported for nickel surfaces $[53,54]$ confirm that the laser treatment results in an actual increase in apparent contact angle in all cases. However, a change in surface energy as a consequence of laser treatment cannot be completely ruled out $[18,22]$, an effect that could change the hydrophobicity of the original smooth surface and give rise to a Wenzel state.

\section{Conclusions}

Ultraviolet laser was used to micro- and nanopattern a nickel thin film sputtered on Ti6Al4V. Three different roughness levels were identified, and two of them could be directly linked to the geometrical rastering parameters (mask size, rastering step). Topographical features such as droplets and craters were related to pressure-induced melt displacement and droplet melt ejection as a consequence of the laser conditions. A twofold to threefold 
increase in contact angle was recorded for water, ethylene glycol and diiodomethane following laser treatment, a behaviour which can be explained in terms the micro- and nanopatterning of the surface.

\section{Aknowledgements}

David thanks the funding support for this research from the NZ Product Accelerator. Also Jérôme Leveneur and John Kennedy at GNS Science for helping with the plasma-sputtering, and Cather Simpson and Fraser McMillan at The Photon Factory for helping with the laser treatment.

\section{References}

[1] Y. Y. Yan, N. Gao, W. Barthlott, Mimicking natural superhydrophobic surfaces and grasping the wetting process: a review on recent progress in preparing superhydrophobic surfaces., Advances in colloid and interface science 169 (2) (2011) 80-105. doi:10.1016/j.cis.2011.08.005.

URL http://www.ncbi.nlm.nih.gov/pubmed/21974918

[2] A. Nakajima, K. Hashimoto, T. Watanabe, K. Takai, G. Yamauchi, A. Fujishima, Transparent superhydrophobic thin films with self-cleaning properties, Langmuir 16 (17) (2000) 7044-7047. doi:10.1021/la000155k.

[3] R. Fürstner, W. Barthlott, C. Neinhuis, P. Walzel, Wetting and selfcleaning properties of artificial superhydrophobic surfaces, Langmuir 21 (3) (2005) 956-961. doi:10.1021/la0401011.

[4] Y. Yoon, D. Kim, J.-B. Lee, Hierarchical micro/nano structures for super-hydrophobic surfaces and super-lyophobic surface against liquid metal, Micro and Nano Systems Letters 2 (1) (2014) 3. doi:10.1186/s40486-014-0003-x.

URL http: //www.mnsl-journal. com/content/2/1/3

[5] S. S. Latthe, C. Terashima, K. Nakata, A. Fujishima, Superhydrophobic surfaces developed by mimicking hierarchical surface morphology of lotus leaf, Molecules 19 (4) (2014) 4256-4283. doi:10.3390/molecules19044256. 
[6] S. Latthe, A. Gurav, C. Maruti, R. Vhatkar, Recent Progress in Preparation of Superhydrophobic Surfaces: A Review, Journal of Surface Engineered Materials and Advanced Technology 02 (02) (2012) 76-94. doi:10.4236/jsemat.2012.22014.

[7] B. Bhushan, Y. C. Jung, K. Koch, Micro-, nano- and hierarchical structures for superhydrophobicity, self-cleaning and low adhesion, Philosophical Transactions of the Royal Society A: Mathematical, Physical and Engineering Sciences 367 (1894) (2009) 1631-1672. doi:10.1098/rsta.2009.0014. URL http://rsta.royalsocietypublishing.org/cgi/doi/10.1098/rsta.2009.0014

[8] L. Feng, S. H. Li, Y. S. Li, H. J. Li, L. J. Zhang, J. Zhai, Y. L. Song, B. Q. Liu, L. Jiang, D. B. Zhu, Super-hydrophobic surfaces: From natural to artificial, Advanced Materials 14 (24) (2002) 1857-1860. doi:DOI 10.1002/adma.200290020. URL <Go to ISI>://000180178700019\nhttp://onlinelibrary.wiley.com/store/10.10

[9] W. Ming, D. Wu, R. Van Benthem, G. De With, Superhydrophobic films from raspberry-like particles, Nano Letters 5 (11) (2005) 22982301. doi:10.1021/nl0517363.

[10] E. Puukilainen, T. Rasilainen, M. Suvanto, T. a. Pakkanen, Superhydrophobic polyolefin surfaces: Controlled micro- and nanostructures, Langmuir 23 (13) (2007) 7263-7268. doi:10.1021/la063588h.

[11] H. M. Shang, Y. Wang, K. Takahashi, G. Z. Cao, D. Li, Y. N. Xia, Nanostructured superhydrophobic surfaces, Journal of Materials Science 40 (13) (2005) 3587-3591. doi:10.1007/s10853-005-2892-9.

[12] N. J. Shirtcliffe, G. McHale, M. I. Newton, G. Chabrol, C. C. Perry, Dual-scale roughness produces unusually waterrepellent surfaces, Advanced Materials 16 (21) (2004) 1929-1932. doi:10.1002/adma.200400315.

[13] P. Tsai, S. Pacheco, C. Pirat, L. Lefferts, D. Lohse, Drop Impact upon Micro- and Nanostructured Superhydrophobic Surfaces, Langmuir 25 (20) (2009) 12293-12298. doi:10.1021/la900330q.

URL http://pubs.acs.org/doi/abs/10.1021/la900330q 
[14] D. Tulli, S. D. Hart, P. Mazumder, A. Carrilero, L. Tian, K. W. Koch, R. Yongsunthon, G. a. Piech, V. Pruneri, Monolithically integrated micro- and nanostructured glass surface with antiglare, antireflection, and superhydrophobic properties, ACS Applied Materials and Interfaces 6 (14) (2014) 11198-11203. doi:10.1021/am5013062. URL http://pubs .acs.org/doi/abs/10.1021/am5013062\nhttp://pubs .acs.org/doi/ab

[15] T. Chong, M. Hong, L. Shi, Laser precision engineering: from microfabrication to nanoprocessing, Laser Photonics Reviews 4 (1) 123-143.

[16] J. Mako, A. Orinak, R. Orinakova, C. Muhmann, O. Petrus, D. Harvanova, J. Vargova, R. Jendzelovsky, J. Radonak, P. Fedorocko, H. Arlinghaus, New nanostructured nickelpolymer nanohybrids with improved surface hydrophobicity and effect on the living cells adhesion, Applied Surface Science 355 (2015) 553-561.

[17] A. Y. Vorobyev, C. Guo, Multifunctional surfaces produced by femtosecond laser pulses, Journal of Applied Physics 117 (3) (2015) 033103. doi:10.1063/1.4905616.

URL http://scitation.aip.org/content/aip/journal/jap/117/3/10.1063/1.4905616

[18] D. V. Ta, A. Dunn, T. J. Wasley, R. W. Kay, J. Stringer, P. J. Smith, C. Connaughton, J. D. Shephard, Nanosecond laser textured superhydrophobic metallic surfaces and their chemical sensing applications, Applied Surface Science 357 (2015) 248-254. doi:10.1016/j.apsusc.2015.09.027. URL http://linkinghub.elsevier.com/retrieve/pii/S0169433215021182

[19] M. Tang, Laser Ablation of Metal Substrates for Super-hydrophobic Effect, Journal of Laser Micro/Nanoengineering 6 (1) (2011) 6-9. doi:10.2961/jlmn.2011.01.0002. URL http://www.jlps.gr.jp/jlmn/index . php?action=laser_volno\&volno=601

[20] R. Jagdheesh, B. Pathiraj, E. Karatay, G. R. B. E. Römer, a. J. Huis In'T Veld, Laser-induced nanoscale superhydrophobic structures on metal surfaces, Langmuir 27 (13) (2011) 8464-8469. doi:10.1021/la2011088.

[21] A.-M. Kietzig, S. G. Hatzikiriakos, P. Englezos, Patterned Superhydrophobic Metallic Surfaces, Langmuir 25 (8) (2009) 4821-4827. 
doi:10.1021/la8037582.

URL http://pubs.acs.org/doi/abs/10.1021/la8037582

[22] A.-m. Kietzig, M. N. Mirvakili, Laser-Patterned Super- Hydrophobic Pure Metallic Substrates : Cassie to Wenzel Wetting Transitions, Journal of Adhesion Science and Technology 25 (October 2013) (2011) 27892809. doi:10.1163/016942410X549988.

[23] S. Moradi, S. Kamal, P. Englezos, S. G. Hatzikiriakos, Femtosecond laser irradiation of metallic surfaces: effects of laser parameters on superhydrophobicity, Nanotechnology 24 (41) (2013) 415302. doi:10.1088/0957-4484/24/41/415302.

URL http: //stacks . iop. org/0957-4484/24/i=41/a=415302?key=crossref . b61fcd05813

[24] M. V. Rukosuyev, J. Lee, S. J. Cho, G. Lim, M. B. G. Jun, One-step fabrication of superhydrophobic hierarchical structures by femtosecond laser ablation, Applied Surface Science 313 (0) (2014) 411-417. doi:http://dx.doi.org/10.1016/j.apsusc.2014.05.224. URL http://www.sciencedirect.com/science/article/pii/S0169433214012689\nhttp:

[25] B. Wu, M. Zhou, J. Li, X. Ye, G. Li, L. Cai, Superhydrophobic surfaces fabricated by microstructuring of stainless steel using a femtosecond laser, Applied Surface Science 256 (1) (2009) 61-66. doi:10.1016/j.apsusc.2009.07.061.

URL http://linkinghub.elsevier.com/retrieve/pii/S0169433209010605

[26] T. Baldacchini, J. E. Carey, M. Zhou, E. Mazur, Superhydrophobic surfaces prepared by microstructuring of silicon using a femtosecond laser., Langmuir : the ACS journal of surfaces and colloids 22 (11) (2006) 4917-4919. doi:10.1021/la053374k.

[27] M. C. Sharp, A. P. Rosowski, P. W. French, Nanosecond laser texturing of aluminium for control of wettability, Proc. of SPIE 9657 (2015) 96570J. doi:10.1117/12.2179929. URL http://proceedings. spiedigitallibrary.org/proceeding. aspx?doi=10.1117/12.

[28] M. Tang, M. Hong, Y. Choo, Z. Tang, D. Chua, Super-hydrophobic transparent surface by femtosecond laser micro-patterned catalyst thin film for carbon nanotube cluster growth, Applied Physics A 101 (2010) 503-508. 
[29] M. Castillejo, P. M. Ossi, L. Zhigilei, Atomic Movies of Laser-Induced Structural and Phase Transformations, in: M. Castillejo, P. M. Ossi, L. Zhigilei (Eds.), Lasers in Materials Science, Vol. 191 of Springer Series in Materials Science, Springer International Publishing, Cham, 2014. doi:10.1007/978-3-319-02898-9.

URL http://link. springer.com/10 . 1007/978-3-319-02898-9

[30] M. Gower, Laser Micromachining, in: C. Webb, J. Jones (Eds.), Handbook of Laser Technology and Applications, Volume III: Applications, IOP Publishing Ltd., 2004, pp. 1661-1691.

[31] M. Stafe, A. Marcu, N. Puscas, Laser-Matter Interaction Below the Plasma Ignition Threshold Intensity, in: M. Stafe, A. Marcu, N. Puscas (Eds.), Pulsed Laser Ablation of Solids, Springer Series in Surface Science 53, Springer-Verlag Berlin Heidelberg, 2014, pp. 53-76.

[32] I. N. Zavestovskaya, Laser Nanocrystallization of Metals, in: V. Veiko, V. I. Konov (Eds.), Fundamentals of Laser-Assisted Micro- and Nanotechnologies, Springer Series in Materials Science 195, Springer-Verlag Berlin Heidelberg, 2014, pp. 51-75.

[33] R. Powell, R. Tye, M. Hickman, The thermal conductivity of nickel, Int. J. Heat Mass Tranfer. 8 (1965) 679-688.

[34] E. Foley, R. Sawyer, Thermal diffusivity of nickel from 25 to 500C, Journal of Applied Physics 35 (1964) 3053.

[35] E. Gamaly, B. Luther-Davies, A. Rode, LaserMatter Interaction Confined Inside the Bulk of a Transparent Solid, in: H. Misawa, S. Juodkazis (Eds.), 3D Laser Microfabrication: Principles and Applications, WileyVCH Verlag GmbH Co., 2006, pp. 5-36.

[36] W. M. Steen, J. Mazumder, Laser Material Processing, Vol. 22, Springer, 2010. doi:10.1007/s00192-011-1389-0.

URL http://www.ncbi.nlm.nih.gov/pubmed/21959656

[37] J. M. Fishburn, M. J. Withford, D. W. Coutts, J. a. Piper, Study of the fluence dependent interplay between laser induced material removal mechanisms in metals: Vaporization, melt displacement and melt ejection, Applied Surface Science 252 (14) (2006) 5182-5188. 
doi:10.1016/j.apsusc.2005.07.053.

URL http://linkinghub.elsevier.com/retrieve/pii/S0169433205010536

[38] A. Fasasi, S. Mwenifumbo, N. Rahbar, J. Chen, M. Li, a.C. Beye, C. Arnold, W. Soboyejo, Nano-second UV laser processed micro-grooves on Ti6Al4V for biomedical applications, Materials Science and Engineering: C 29 (1) (2009) 5-13. doi:10.1016/j.msec.2008.05.002. URL http://linkinghub.elsevier.com/retrieve/pii/S0928493108000908

[39] J. M. Fishburn, R. P. Mildren, D. Kapitan, M. J. Withford, D. J. W. Brown, J. a. Piper, Exploring the explosive ablation regime of metals in nanosecond micromachining, in: C. R. Phipps, M. Niino (Eds.), SPIE Volume 3885, Vol. 3885, 2000, pp. 453-460. doi:10.1117/12.376996.

URL http: //proceedings . spiedigitallibrary . org/proceeding . aspx?articleid=91295

[40] S. Chen, Melting and surface deformation in pulsed laser surface micromodification of Ni-P disks, Journal of Heat Transfer 122 (February 2000) (2000) 107-112.

URL http://heattransfer.asmedigitalcollection.asme.org/article.aspx?articleid

[41] L. Dobrzaski, A. Drygaa, K. Goombek, P. Panek, E. Bielaska, P. Ziba, Laser surface treatment of multicrystalline silicon for enhancing optical properties, Journal of Materials Processing Technology 201 (1-3) (2008) 291-296. doi:10.1016/j.jmatprotec.2007.11.278.

URL http://www.sciencedirect.com/science/article/pii/S0924013607011806

[42] A. Semerok, B. Salle, J. Wagner, G. Petite, Femtosecond, picosecond, and nanosecond laser microablation: Laser plasma and crater investigation, Laser and Particle Beams 20 (2002) 67-72.

URL http://proceedings. spiedigitallibrary .org/proceeding. aspx?articleid=88761

[43] Z. Andreic, V. Henc-Bartolic, D. Gracin, M. Stubicar, Droplet formation during laser sputtering of silicon, Applied Surface Science 136 (1998) 7380 .

[44] J. L. Huang, N. Warnken, J.-C. Gebelin, M. Strangwood, R. C. Reed, On the mechanism of porosity formation during welding of titanium alloys, Acta Materialia 60 (6-7) (2012) 3215-3225. doi:10.1016/j.actamat.2012.02.035. URL http://www. sciencedirect.com/science/article/pii/S1359645412001437 
[45] J. C. Ion, Cladding, in: Laser Processing of Engineering Materials, Elsevier, 2005, pp. 296-326. doi:10.1016/B978-075066079-2/50015-5.

URL http://www.sciencedirect.com/science/article/pii/B9780750660792500155

[46] E. Akman, a. Demir, T. Canel, T. Snmazçelik, Laser welding of Ti6Al4V titanium alloys, Journal of Materials Processing Technology 209 (8) (2009) 3705-3713. doi:10.1016/j.jmatprotec.2008.08.026. URL http://linkinghub.elsevier.com/retrieve/pii/S0924013608006572

[47] A. Tran, M. Hyland, K. Shinoda, S. Sampath, Influence of substrate surface conditions on the deposition and spreading of molten droplets, Thin Solid Films 519 (8) (2011) 2445-2456. doi:10.1016/j.tsf.2010.11.047. URL http://www. scopus.com/inward/record. url?eid=2-s2.0-79551490298\&partnerID=

[48] Y. Yang, J. Yang, L. Xue, Y. Guo, Surface patterning on periodicity of femtosecond laser-induced ripples, Applied Physics Letters 97 (14) (2010) 141101. doi:10.1063/1.3495785. URL http://scitation.aip.org/content/aip/journal/apl/97/14/10.1063/1.3495785

[49] M. Huang, F. Zhao, Y. Cheng, N. Xu, Z. Xu, Origin of laser-induced near-subwavelength ripples: interference between surface plasmons and incident laser., ACS nano 3 (12) (2009) 4062-70. doi:10.1021/nn900654v. URL http://www.ncbi.nlm.nih.gov/pubmed/20025303

[50] G. D. Tsibidis, E. Stratakis, P. a. Loukakos, C. Fotakis, Controlled ultrashort-pulse laser-induced ripple formation on semiconductors, Applied Physics A 114 (1) (2013) 57-68. doi:10.1007/s00339-013-8113-5. URL http://link. springer.com/10.1007/s00339-013-8113-5

[51] J. Sipe, J. Young, J. Preston, H. V. Driel, Laser-induced periodic surface structure. I. Theory, Physical Review B 27 (2). URL http://journals . aps .org/prb/abstract/10.1103/PhysRevB .27.1141

[52] A. K. Kota, G. Kwon, A. Tuteja, The design and applications of superomniphobic surfaces, NPG Asia Materials 6 (7) (2014) e109. doi:10.1038/am.2014.34. URL http://dx.doi.org/10.1038/am.2014.34

[53] T. Ahsan, Influence of surface properties of metal leadframes on moldcompound metal adhesion in semiconductor packaging, in: K. Mittal 
(Ed.), Contact Angle, Wettability and Adhesion, Volume 4, VSP, 2006, pp. 525-529.

[54] F. a. Lopes, P. Morin, R. Oliveira, L. F. Melo, The influence of nickel on the adhesion ability of Desulfovibrio desulfuricans, Colloids and Surfaces B: Biointerfaces 46 (2) (2005) 127-133. doi:10.1016/j.colsurfb.2005.07.020. 
Click here to access/download Supporting Information LaTeX submission - PSSA - rev.zip 